CLINICAL STUDY

\title{
The appearance of the adrenal glands on computed tomography in multiple endocrine neoplasia type 1
}

\author{
S A Whitley ${ }^{1, *}$, V J Moyes ${ }^{2, *}, \mathrm{~K}_{\text {M Park }}{ }^{1}$, A M Brooke ${ }^{2}$, A B Grossman ${ }^{2}$, S L Chew ${ }^{2}$, A G Rockall ${ }^{1}$, J P Monson ${ }^{2}$ \\ and R H Reznek ${ }^{1}$ \\ ${ }^{1}$ Departments of Diagnostic Imaging and ${ }^{2}$ Centre for Endocrinology, St Bartholomew's Hospital, Barts and the London NHS Trust and QMUL, London, UK \\ (Correspondence should be addressed to R H Reznek who is now at Centre for Cancer Imaging, Institute of Cancer, Barts and The London School of Medicine \\ and Dentistry, Dominion House, 59 Bartholomew Close, London EC1A 7ED, UK; Email: r.h.reznek@qmul.ac.uk)
}

*(S A Whitley and V J Moyes contributed equally to this work)

\begin{abstract}
Aims: To review the morphology of the adrenal glands in multiple endocrine neoplasia type 1 (MEN1) on computed tomography (CT) to compare the results with established normal values for adrenal size and nodularity and to correlate adrenal size with serum cortisol secretory dynamics.

Materials and methods: Two observers independently reviewed the adrenal CT in 28 patients with MEN1, measuring the maximum width of the body of the gland and the medial and lateral limbs. Incidence and location of nodules $>5 \mathrm{~mm}$ within the gland were recorded. Following exclusion of known cases of Cushing's syndrome, adrenal gland size was compared with previously documented normative data. Adrenal gland size was compared between patients with normal and abnormal cortisol dynamics.

Results: Comparison of mean adrenal size in MEN1 patients with normative data showed that the adrenal limbs were significantly larger in MEN1 than normal $(P<0.0001$ in all four limbs). Adrenal body was also significantly larger $(P<0.05)$. Nodules were demonstrated in $17(60 \%)$ of patients (versus $0.4-2 \%$ in the normal population). No statistically significant correlation was demonstrated between adrenal limb hyperplasia and abnormal cortisol dynamics.

Conclusions: In patients with MEN1, adrenal limb hyperplasia and adrenal nodules are significantly more common than in the normal population, a phenomenon not previously documented in a quantitative manner. There was no significant correlation between adrenal limb hyperplasia and abnormal cortisol dynamics.
\end{abstract}

European Journal of Endocrinology 159 819-824

\section{Introduction}

Multiple endocrine neoplasia type 1 (MEN1) is an inherited, autosomal dominant cancer syndrome. Tumours classically described in MEN1 are neoplasia of the anterior pituitary, parathyroid glands and endocrine pancreas but other neuroendocrine tumours, lipomas and ependymomas are also seen (1). MEN1 gene has been located on chromosome 11q13 and encodes for a nuclear protein called menin that is thought to have a tumour suppressor function (2).

Although observational studies have reported adrenal abnormalities in $30-40 \%$ of MEN1 patients including hyperplasia, nodularity and neoplasia, the exact frequencies and nature of the abnormalities have not been fully documented. Where hyperplasia is suspected, measurements have not been performed, nor have the size of the glands been compared with normal values, making the changes arbitrary $(3,4)$. Interestingly, those benign adrenal lesions that have been studied do not show inactivation of the remaining non-mutated menin gene, suggesting that they do not fit a classical two-hit theory of neoplasia (4). Initial reports that adrenal lesions are found only in patients with pancreatic hypersecretion have not subsequently been proven (5).

In this study, we reviewed the computed tomography (CT) imaging of the adrenal glands in a cohort of patients with MEN1, comparing the size of their adrenals with established normal values for adrenal size, as described by Vincent et al. (6). Modern CT is now capable of identifying small nodules, often less than $5 \mathrm{~mm}$. We have documented the presence, number and size of any adrenal nodules and compared these findings with those described in the normal population (7). The majority of adrenal lesions in MEN1 have previously been reported to be non-functioning $(3,8,9)$. We reviewed the patients' serum cortisol secretory dynamics and sought potential correlations with adrenal morphology. 


\section{Methods}

\section{Patients and endocrine investigation}

The diagnosis of MEN1 was made either by genetic confirmation or a positive family history with two or more typical endocrine lesions. The diagnoses of classical MEN1 lesions were made using the following modalities: MRI pituitary with standard anterior pituitary function testing, serum PTH and calcium in conjunction with ultrasound and sestamibi radionuclide parathyroid localisation and CT scanning of the abdomen with fasting gut peptides for detection of islet cell tumours. In total, 37 patients fulfilled this criterion. Abdominal CT imaging was available in 28 patients with confirmed MEN1; biochemical data were accessible for 21 of these patients. Three patients with known pituitary dependent Cushing's were excluded from the adrenal size analyses due to the predictability of adrenal gland enlargement and abnormal cortisol dynamics. One patient with bilateral adrenal macronodular hyperplasia was similarly excluded.

Low-dose dexamethasone suppression test (LDDST; dexamethasone $0.5 \mathrm{mg}$ orally 6 hourly for $48 \mathrm{~h}$ ) and/or midnight serum cortisol (asleep) results were obtained from a retrospective case notes study and by recalling (where possible) and performing LDDST in patients with no prior results. Normal results were defined as a cortisol level of $<50 \mathrm{nmol} / \mathrm{l}$ for both tests. Where more than one result was available, the lowest reliable (asleep) midnight cortisol was used. Where only unreliable (awake) midnight cortisol results were available the result of the LDDST was used. Table 1 shows the demographics and clinical diagnoses of the cohort studied.

\section{Imaging technique}

CT was available on all 37 patients, however, electronic CT data, suitable for measurement and detailed analysis, was available in only 28 patients, and these formed the cohort for study. These 28 patients were scanned for various clinical indications, including assessment and screening for pancreatic and adrenal neoplasia and liver metastases. In patients in whom more than one CT examination had been performed, the scan closest to the time of diagnosis was studied. The scans dated from 1992 to 2004 and were performed on GE Lightspeed Ultra, GE Hispeed ZXi and GE Hispeed Advantage RP CT scanners (General Electric, Waukesha, WI, USA). Contiguous slice thickness varied between patients; 17 patients at $5 \mathrm{~mm}, 9$ patients at $3 \mathrm{~mm}, 2$ patients at $3.5 \mathrm{~mm}$ and 1 patient at $10 \mathrm{~mm}$. In all patients contrast medium was injected intravenously.

Table 1 Clinical features and serum cortisol dynamics of MEN1 patients.

\begin{tabular}{|c|c|c|c|c|}
\hline \multirow[b]{2}{*}{ Patient numbers } & \multirow[b]{2}{*}{ Gender/age } & \multirow[b]{2}{*}{ Diagnoses } & \multicolumn{2}{|c|}{ Cortisol (nmol/l) } \\
\hline & & & LDDST & Midnight cortisol \\
\hline 1 & M 42 & PTH, Gastric Carcinoid & / & $<50$ asleep \\
\hline 2 & F 46 & PTH, PRL & $<20$ & / \\
\hline 3 & F 60 & PTH, Pituitary Cushing's & $<50$ & 64 awake \\
\hline 4 & F 50 & PTH, Gastrinoma, Insulinoma & $<20$ & / \\
\hline 5 & F 35 & PTH, PRL, islet cell tumour & / & / \\
\hline 6 & F 72 & No data available & / & / \\
\hline 7 & F 46 & PTH, bronchial carcinoid & $<50$ & 68 asleep \\
\hline 8 & M 67 & PTH, gastrinoma, thymic carcinoid & 85 & / \\
\hline 9 & $\mathrm{~F} 40$ & PTH, NFPA & / & $<20$ asleep \\
\hline 10 & M 48 & PTH, NFPA, islet cell tumour & / & / \\
\hline 11 & F 64 & PTH, acromegaly, carcinoid & / & $<50$ asleep \\
\hline 12 & M 59 & PTH, acromegaly & $<20$ & / \\
\hline 13 & F 52 & PTH, NFPA, glucagonoma & $<50$ & $<50$ asleep \\
\hline 16 & F 52 & PTH, gastrinoma, NFPA & $<50$ & 95 awake \\
\hline 17 & M 49 & PTH, NFPA, islet cell tumour & / & 31 asleep \\
\hline 18 & M 60 & PTH, NFPA, insulinoma, gastrinoma & / & 63 asleep \\
\hline 19 & F 87 & PTH, insulinoma & / & l \\
\hline 20 & M 57 & PTH, insulinoma, gastrinoma & / & 80 asleep \\
\hline 21 & M 74 & PTH, PRL, gastrinoma & 313 & 80 asleep \\
\hline 22 & M 53 & PTH & 21 & / \\
\hline 23 & F 46 & PTH, gastrinoma & $<50$ & 177 asleep \\
\hline 24 & F 87 & No data available & / & / \\
\hline 25 & M 66 & PTH, acromegaly, gastrinoma & $<50$ & / \\
\hline 26 & F 53 & PTH, NFPA, gastrinoma & $<50$ & 72 asleep \\
\hline 27 & M 88 & No data available & / & / \\
\hline 28 & F 75 & PTH, Pituitary Cushing's & / & $/^{*}$ \\
\hline
\end{tabular}

Cortisol dynamics are determined by nadir serum cortisol on low-dose dexamethasone suppression test and/or midnight serum cortisol. Normality of cortisol secretion is demonstrated by a sleeping midnight cortisol result of $<50 \mathrm{nmol} / \mathrm{l}$ and/or a nadir serum cortisol of $<50 \mathrm{nmol} / \mathrm{l}$ on low-dose dexamethasone suppression test. *denotes patient with known pituitary dependent Cushing's syndrome, **denotes patient with bilateral macronodular adrenal hyperplasia. 


\section{Image interpretation}

The images were reviewed on a remote console and interpreted by two radiologists experienced at adrenal imaging (AGR and RHR). Initially, two scans were reviewed together by the observers to ensure similar measurements were undertaken. The remaining scans were then reviewed by the observers independently with nine of these scans reviewed by both in order to calculate inter-observer variability. Measurements were made according to previously published methodology $(6,10)$. These included: the maximum width perpendicular to the long axis of the gland and the maximum width of the medial and lateral limbs. The presence of nodules over $5 \mathrm{~mm}$ and their size was recorded.

\section{Statistical analysis}

The data obtained were entered into an Excel spreadsheet. Data distribution were skewed due to the presence of bilateral autonomous macronodular hyperplasia; exclusion of this case resulted in a normal distribution. An unpaired $t$-test was used to compare the adrenal body and limb size in the MEN1 cohort with previously published normative data from Vincent et al. Inter-rater reliability was calculated for the patients for whom measurement overlapped between observers. Comparison of adrenal body and limb measurements between the normal and abnormal cortisol dynamic group was performed using an unpaired $t$-test.

\section{Results}

\section{Size of gland}

The average measurements and range of measurements for the right and left adrenal glands in our MEN1 cohort are shown in Table 2. Following exclusion of patients with known Cushing's syndrome, comparison was made with previously published normative data from Vincent et al. The adrenal limbs were significantly larger in the MEN1 cohort compared with the normal population
$(P<0.0001$ in all four limbs). The body was also significantly larger $(P=0.0158$ and 0.0490$)$. Furthermore, 7 out of the 24 patients had all four limbs more than 2 s.D. above the normal mean, 1 lout of the 24 had at least three limbs more than 2 s.D. above the normal mean and 20 out of the 24 patients had at least one limb larger than 2 s.D. above normal mean (Table 3).

\section{Inter-rater reliability}

Of the 28 patients with MEN1, two were measured by RHR and AGR together, nine others measured independently by both RHR and AGR, seven others measured by AGR alone, ten others by RHR alone. For the nine patients with independent measurements by two observers the correlation between the observations was measured. Each patient yields six values and using a one-tailed test; five out of the six tests yielded a significant positive correlation (Table 4). As Table 4 shows, only the left lateral measurement indicated a poor correlation between the two observers. However, the average difference between observers in this group of nine patients was only $0.8 \mathrm{~mm}$, so agreement between observers was thought to be acceptable.

\section{Nodularity, percentage of adrenals with nodules}

In 17 out of the $27(60 \%)$ patients one or more adrenal nodule over the size of $5 \mathrm{~mm}$ was found, three patients had a nodule or nodules that were greater than $10 \mathrm{~mm}$, while the rest were between 5 and $10 \mathrm{~mm}$. This compares with $0.4-2 \%$ in the normal population (7). The nodules were predominantly focal $(88 \%)$ rather than multiple (12\%) (Fig. 1).

\section{Adrenocortical function}

The patients were grouped according to whether they had normal or abnormal serum cortisol dynamics according to the LDDST and midnight cortisol results. Normal

Table 2 Mean adrenal gland measurements for the MEN1 and normal populations.

\begin{tabular}{|c|c|c|c|c|c|c|c|c|c|c|}
\hline \multirow[b]{2}{*}{$\begin{array}{l}\text { Adrenal } \\
\text { position }\end{array}$} & \multicolumn{3}{|c|}{ MEN1 (mm) } & \multicolumn{3}{|c|}{ Normal $(\mathrm{mm})$} & \multicolumn{4}{|c|}{ Difference between MEN1 \& normal (mm) } \\
\hline & $N$ & $\begin{array}{l}\text { Mean } \\
\text { (S.D.) }\end{array}$ & S.E.M. & $N$ & $\begin{array}{l}\text { Mean } \\
\text { (S.D.) }\end{array}$ & S.E.M. & Mean & $t$ & df & $P$-value \\
\hline \multicolumn{11}{|l|}{ Body } \\
\hline Right & 24 & $7.45(2.71)$ & 0.89 & 55 & $6.1(2)$ & 0.27 & 1.350 & 2.468 & 77 & 0.0158 \\
\hline Left & 24 & $9.11(3.18)$ & 1.04 & 55 & $7.9(2.1)$ & 0.28 & 1.210 & 2.000 & 77 & 0.0490 \\
\hline \multicolumn{11}{|l|}{ Medial } \\
\hline Right & 24 & $4.65(1.51)$ & 0.45 & 50 & $2.8(0.8)$ & 0.11 & 1.850 & 6.905 & 72 & $<0.0001$ \\
\hline Left & 24 & $5.29(1.73)$ & 0.79 & 34 & $3.3(0.9)$ & 0.15 & 1.990 & 5.714 & 56 & $<0.0001$ \\
\hline \multicolumn{11}{|l|}{ Lateral } \\
\hline Right & 24 & $4.92(1.60)$ & 0.49 & 38 & $2.8(0.6)$ & 0.10 & 2.120 & 7.412 & 60 & $<0.0001$ \\
\hline Left & 24 & $4.98(1.59)$ & 0.67 & 42 & $3.0(0.1)$ & 0.02 & 1.491 & 8.090 & 64 & $<0.0001$ \\
\hline
\end{tabular}

This table shows the means of the sizes of the individual bodies and limbs of the adrenals in the MEN1 and normal population with comparison using an unpaired $t$-test. 
Table 3 Frequency of adrenal measurements $>2$ S.D. above mean of normal population.

\begin{tabular}{lll}
\hline & $\boldsymbol{N}$ & Frequency of limbs $>2$ s.D. \\
\hline Body & & \\
Right & 24 & $3(12.5 \%)$ \\
Left & 24 & $4(16.6 \%)$ \\
Medial & 24 & $12(50 \%)$ \\
Right & 24 & $12(50 \%)$ \\
Left & 24 & $11(45.8 \%)$ \\
Lateral & 24 & $18(75 \%)$ \\
$\quad$ Right & & \\
Left & 24 \\
\hline
\end{tabular}

This table demonstrates the comparison of the adrenal size of the MEN1 cohort with a normal population (from Vincent et al.). This demonstrates the prevalence of adrenal limb size $>2$ S.D. above the mean of a normal population.

cortisol dynamics are defined as a serum cortisol of $<50 \mathrm{nmol} / \mathrm{l}$ for both tests. Where available, accurately measured asleep midnight cortisol results have been used in preference to the low-dose dexamethasone suppression test; a sleeping midnight cortisol result of $<50 \mathrm{nmol} / \mathrm{l}$ excludes abnormal cortisol secretory dynamics (Table 5 ). Cushing's disease was diagnosed on the basis of abnormal serum cortisol secretion combined with a diagnostic central to peripheral gradient on bilateral simultaneous inferior petrosal sinus sampling, as previously described (11). There was no statistically significant correlation between adrenal limb hyperplasia and abnormal cortisol dynamics (Table 5).

\section{Discussion}

In this retrospective review, we have for the first time directly measured the size of the adrenal glands in patients with MEN1 using electronic callipers and established methodology (6). This methodology has been used repeatedly in other studies (12-14). The methodology was confirmed within the study by showing that two independent observers had inter-observer variability

Table 4 Inter-rater reliability.

\begin{tabular}{ccll}
\hline & $\boldsymbol{r}$ & \multicolumn{1}{c}{$\boldsymbol{P}$} & $\boldsymbol{N}$ \\
\hline $\begin{array}{c}\text { Body } \\
\text { Right }\end{array}$ & 0.64 & 0.031 & \\
$\begin{array}{l}\text { Left } \\
\text { Medial }\end{array}$ & 0.63 & 0.034 & 9 \\
$\begin{array}{l}\text { Right } \\
\text { Left }\end{array}$ & 0.66 & 0.026 & 9 \\
Lateral & 0.87 & 0.00103 & 9 \\
Right & & 0.012 & \\
Left & 0.78 & 0.272 & 8 \\
\hline
\end{tabular}

The adrenal size of nine patients was assessed independently by two observers and the correlation was measured; five out of six tests yielded a positive correlation. Despite the lack of correlation for the left lateral measurement, the average difference between observers in the left lateral measurement was only $0.8 \mathrm{~mm}$.
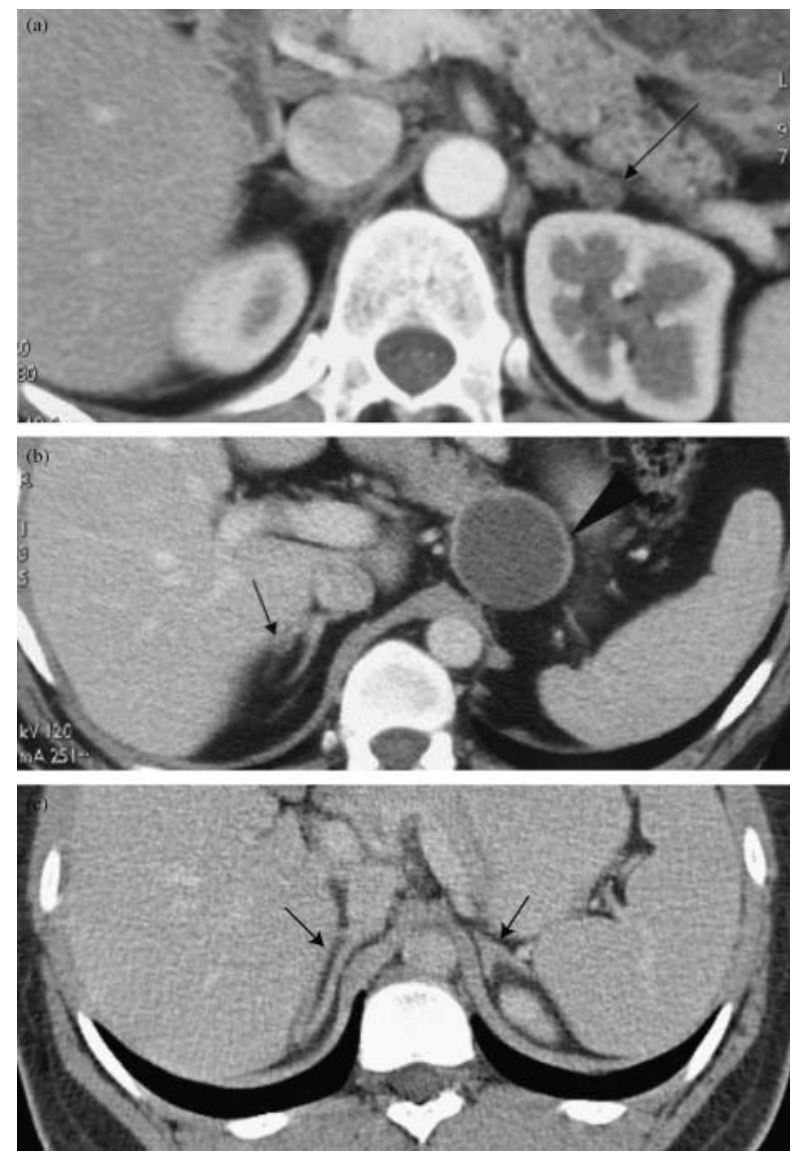

Figure 1 Contrast enhanced axial CT images of the adrenal glands. (a) 41-year-old female patient with MEN1 demonstrates a $1 \mathrm{~cm}$ nodule arising from the lateral limb of the left adrenal (black arrow). (b) 46-year-old male patient with MEN1 demonstrates small $0.8 \mathrm{~cm}$ nodule arising from lateral limb of the right adrenal (black arrow). A pancreatic cyst is also present (black arrowhead). (c) Normal sized adrenal glands for comparison.

within an acceptable range. We have also for the first time in MEN1 compared the results of the measurements to established normal values (6).

Our results show that the adrenal limbs in patients with MEN1 are significantly larger than the adrenal limbs in a normal population. To a lesser extent, a difference was also detected in adrenal body size. Dobbie and Symington (15) showed that the limbs of the adrenal gland consist predominantly of adrenal cortical tissue with little or no medullary tissue, which is maximal in the body. Enlargement of the limbs indicates adrenal cortical expansion and our study therefore confirms previous reports that adrenocortical hyperplasia is part of the MEN1 syndrome. Overall, the mean thickness of the adrenal limbs in MEN1 is significantly larger than that of the normal population. More significantly, 20 out of the $24(83 \%)$ had at least one limb 2 s.D. larger than the normal mean, while 7 out of the $24(29 \%)$ had all four limbs more than 2 s.D. larger. There were no 
Table 5 Mean size of adrenals according to the serum cortisol secretory dynamics.

\begin{tabular}{|c|c|c|c|c|c|c|c|c|}
\hline & & \multicolumn{3}{|c|}{$\begin{array}{l}\text { Normal cortisol } \\
\text { dynamics } n=12\end{array}$} & \multicolumn{4}{|c|}{$\begin{array}{c}\text { Abnormal cortisol } \\
\text { dynamics } n=7\end{array}$} \\
\hline & & Mean & S.D. & S.E.M. & Mean & S.D. & S.E.M. & $\begin{array}{c}P \\
\text { value }\end{array}$ \\
\hline \multirow{2}{*}{$\begin{array}{l}\text { Body } \\
\text { width } \\
(\mathrm{mm})\end{array}$} & Right & 5.82 & 2.29 & 0.66 & 8.45 & 1.48 & 0.56 & 0.015 \\
\hline & Left & 7.63 & 3.69 & 1.06 & 10.30 & 2.02 & 0.76 & 0.098 \\
\hline \multirow{2}{*}{$\begin{array}{l}\text { Medial } \\
\operatorname{limb} \\
(\mathrm{mm})\end{array}$} & Right & 4.02 & 1.41 & 0.41 & 4.86 & 0.94 & 0.35 & 0.178 \\
\hline & Left & 4.43 & 1.55 & 0.45 & 5.76 & 1.21 & 0.45 & 0.069 \\
\hline \multirow{2}{*}{$\begin{array}{l}\text { Lateral } \\
\operatorname{limb} \\
(\mathrm{mm})\end{array}$} & Right & 4.24 & 1.43 & 0.41 & 5.14 & 0.92 & 0.35 & 0.156 \\
\hline & Left & 4.48 & 1.16 & 0.33 & 5.51 & 1.41 & 0.53 & 0.102 \\
\hline
\end{tabular}

The adrenal size was compared between the groups of patients with norma versus abnormal cortisol secretory dynamics, as determined by midnight cortisol or low-dose dexamethasone suppression test. Patients with known Cushing's syndrome were excluded from the comparison. The adrenal size was compared using an unpaired $t$-test.

distinguishing clinical features of the four patients who lacked adrenal hyperplasia, all had hyperparathyroidism, three had pituitary tumours and three had pancreatic endocrine tumours. A previous study by Skogseid et al. (16) suggested that adrenal enlargement was associated with the presence of pancreatic endocrine tumours. This does not appear to be evident within our cohort; three out of four with normal adrenal size and 7 out of 24 with adrenal hyperplasia had confirmed pancreatic endocrine tumours.

There was no statistically significant correlation between adrenal hyperplasia and abnormal cortisol dynamics, although we note our small sample size. The association of adrenal limb hyperplasia with MEN1 does pose the question as to whether MEN1 patients should be routinely assessed for abnormal cortisol dynamics. Chronic, autonomous cortisol production may be associated with hypertension, hyperlipidaemia, insulin resistance and osteopenia, without necessarily the development of overt Cushing's syndrome (17). A variety of methods may be used to assess cortisol status as demonstrated in this study, including standard lowdose or overnight dexamethasone suppression tests and the assessment of circadian rhythm with midnight cortisol measurements.

The relative rarity of MEN1 inevitably reduces the numbers of patients available for a study such as this. Furthermore, we acknowledge that the retrospective nature of the study will necessarily introduce an element of bias with regard to availability of relevant data. However, notwithstanding these caveats, our study shows that in patients with MEN1, adrenal limb hyperplasia and adrenal nodules are significantly more common than in the normal population; a phenomenon not previously documented with precise quantitation.
However, in this small series there was no statistically significant correlation between adrenal limb hyperplasia and abnormal cortisol dynamics.

\section{Declaration of interest}

There is no conflict of interest that could be perceived as prejudicing the impartiality of the research reported.

\section{Funding}

This research did not receive any specific grant from any funding agency in the public, commercial or not for profit sector.

\section{References}

1 Pannett AA \& Thakker RV. Multiple endocrine neoplasia type 1. Endocrine-Related Cancer 19996 449-473.

2 Larsson C \& Friedman E. Localization and identification of the multiple endocrine neoplasia type 1 disease gene. Endocrinology and Metabolism Clinics of North America 199423 67-79.

3 Langer P, Cupisti K, Bartsch DK, Nies C, Goretzki PE, Rothmund M \& Roher HD. Adrenal involvement in multiple endocrine neoplasia type 1. World Journal of Surgery 200226 891-896.

4 Skogseid B, Larsson C, Lindgren PG, Kvanta E, Rastad J, Theodorsson E, Wide L, Wilander E \& Oberg K. Clinical and genetic features of adrenocortical lesions in multiple endocrine neoplasia type 1. Journal of Clinical Endocrinology and Metabolism $19927576-81$.

5 Barzon L, Pasquali C, Grigoletto C, Pedrazzoli S, Boscaro M \& Fallo F. Multiple endocrine neoplasia type 1 and adrenal lesions. Journal of Urology 2001166 24-27.

6 Vincent JM, Morrison ID, Armstrong P \& Reznek RH. The size of normal adrenal glands on computed tomography. Clinical Radiology 199449 453-455.

7 Barzon L, Sonino N, Fallo F, Palu G \& Boscaro M. Prevalence and natural history of adrenal incidentalomas. European Journal of Endocrinology 2003149 273-285.

8 Burgess JR, Harle RA, Tucker P, Parameswaran V, Davies P, Greenaway TM \& Shepherd JJ. Adrenal lesions in a large kindred with multiple endocrine neoplasia type 1. Archives of Surgery 1996 $131699-702$.

9 Skogseid B, Rastad J, Gobl A, Larsson C, Backlin K, Juhlin C, Akerström G \& Oberg K. Adrenal lesion in multiple endocrine neoplasia type 1. Surgery 1995118 1077-1082.

10 Vincent JM, Morrison ID, Armstrong P \& Reznek RH. Computed tomography of diffuse, non-metastatic enlargement of the adrenal glands in patients with malignant disease. Clinical Radiology 1994 49 456-460.

11 Kaltsas GA, Giannulis MG, Newell-Price JDC, Dacie JE, Thakkar C, Afshar F, Monson JP, Grossman AB, Besser GM \& Trainer PG. A critical analysis of the value of simultaneous inferior petrosal sinus sampling in Cushing's disease and the occult ectopic adrenocorticotropin syndrome. Journal of Clinical Endocrinology and Metabolism $1999 \mathbf{8 4} 487-492$.

12 Lingam RK, Sohaib SA, Vlahos I, Rockall AG, Isidori AM, Monson JP, Grossman A \& Reznek RH. CT of primary hyperaldosteronism (Conn's syndrome): the value of measuring the adrenal gland. American Journal of Roentgenology 2003181 843-849.

13 Sohaib SA, Hanson JA, Newell-Price JD, Trainer PJ, Monson JP, Grossman AB, Besser GM \& Reznek RH. CT appearance of the adrenal glands in adrenocorticotrophic hormone-dependent Cushing's syndrome. American Journal of Roentgenology 1999 172 997-1002. 
14 Scott LV, Teh J, Reznek R, Martin A, Sohaib A \& Dinan TG. Small adrenal glands in chronic fatigue syndrome: a preliminary computer tomography study. Psychoneuroendocrinology 199924 $759-768$.

15 Dobbie JW \& Symington T. The human adrenal gland with special reference to the vasculature. Journal of Endocrinology $1966 \mathbf{3 4}$ 479-489.

16 Skogseid B, Eriksson B, Lundqvist G, Lorelius LE, Rastad J, Wide L, Akerstrom G \& Oberg K. Multiple endocrine neoplasia type 1: a 10 -year prospective screening study in four kindreds. Journal of Clinical Endocrinology and Metabolism 199173 281-287.
17 Tauchmanova L, Rossi R, Biondi B, Pulcrano M, Nuzzo V, Palmieri EA, Fazio S \& Lombardi G. Patients with subclinical Cushing's syndrome due to adrenal adenoma have increased cardiovascular risk. Journal of Clinical Endocrinology and Metabolism $2002874872-4878$.

Received 1 September 2008

Accepted 24 September 2008 